\title{
ERRATUM
}

\section{Identificación Morfológica y Molecular de Prosapia simulans (Walker) (Hemiptera: Cercopidae), y Selección y Mecanismos de Resistencia a este Salivazo en Híbridos de Brachiaria}

[Neotropical Entomology, July-August, 2007, 36(4): 547-554]

\author{
Ulises Castro $^{1}$, Cesar Cardona ${ }^{1}$, Jorge Vera-Graziano ${ }^{2}$, John Miles $^{1}$ y Ramón Garza-Garcia ${ }^{3}$ \\ ${ }^{1}$ Centro Internacional de Agricultura Tropical - CIAT, Apartado Aéreo 6713, Cali, Colombia \\ ucastro@colpos.mx,c.cardona@cgiar.org,jmiles@cgiar.org \\ ${ }^{2}$ Colegio de Postgraduados, km 36.5 Carr. México-Texcoco, Montecillos Edo. de México \\ México C.P.56230,graziano@colpos.mx \\ ${ }^{3}$ INIFAP Campo Experimental Valle de México. Carr. Los Reyes-Lechería km 18.5 Chapingo. Texcoco \\ Edo.de México, C.P. 56230, rgarzagarcia@yahoo.com.mx
}

Received 07/III/06. Accepted 07/II/07

At the page 548, the phrase: "Se estima que en Brasil hay cerca de 154,000,000 ha sembradas con Brachiaria llamada Marandu (EMBRAPA 2006)" is incorrect.

The correct form is given bellow:

"Se estima que en Brasil hay cerca de 154,000,000 ha sembradas con pastos, de ellas 39\% corresponden a Brachiaria llamada Marandu (EMBRAPA 2006)" 